\title{
Size Controlled Synthesis of One - dimensional Single Crystalline Hydroxyapatite Nanorods by Hydrothermal Method
}

\author{
Sneha M, Meenakshi Sundaram N*, Kandaswamy A \\ Department of Biomedical Engineering, PSG College of Technology, India
}

Copyright (C) 2016 by authors, all rights reserved. Authors agree that this article remains permanently open access under the terms of the Creative Commons Attribution License 4.0 International License

\begin{abstract}
Hydroayapatite (HAp) nanorods were widely used in biomedical fields such as multifunctional drug delivery systems, bone tissue damages and for dental applications. Here, rod shaped HAp nanoparticles with uniform morphology and controllable size were successfully synthesized without any templates by hydrothermal method. Powder X-Ray diffractometer (XRD), Optical Micrographs (OM), Nitrogen adsorption and desorption studies (BET), Field Emission Scanning Electron Microscope (FE-SEM) and Transmission Electron Microscope (TEM) were used to characterize the structure and composition of the prepared HAp samples. The biocompatibility of the prepared nanorods was tested against MG 63 human osteosarcoma cell lines using MTT assay. The results confirmed that the synthesized HAp nanorods are biocompatible, high purity in nature and high aspect ratio with mean width of $10 \mathrm{~nm}$ and mean length of $100 \mathrm{~nm}$. Thus the prepared hydroayapatite nanorods can be used as drug carrying vehicles for hard tissue repair, bone regeneration, bone tissue engineering applications and as strength-enhancing additives for the preparation of biocompatible nanocomposites with improved mechanical properties.
\end{abstract}

Keywords Hydroxyapatite, Rods, Hydrothermal, Osteosarcoma, Tissue Engineering

\section{Introduction}

Calcium phosphates with $\mathrm{Ca} / \mathrm{P}$ ratio between $1.5-2.0$ belongs to the group of bioactive inorganics. It is classified into three main compounds namely, tetraphosphate $\left(\mathrm{Ca}_{4} \mathrm{P}_{2} \mathrm{O}_{9}\right)$, hydroxyapatite $\mathrm{Ca}_{10}\left(\mathrm{PO}_{4}\right)_{6}(\mathrm{OH})_{2}$ and tricalciumphosphate $\left(\mathrm{Ca}_{3}\left(\mathrm{PO}_{4}\right)_{2}\right.$. Among these, hydroxyapatite is the most stable form of calcium phosphate and major component of bones and teeth [1]. HAp are highly suitable for applications in nanomedicine especially in the area of bone reconstruction and cancer treatment [2]. It has the ability to form chemical bonding with bone tissue during in vivo conditions and to conduct bone tissue growth on the implanted materials [3].The important properties such as bioactivity, biocompatibility, stability and mechanical properties of HAp are determined by its crystal shape, size, composition and structure [4]. The synthesis of HAp with controlled particle size and shape is important in order to improve the contact and stability at the natural bone interface [5].There are many methods developed for synthesizing of hydroxyapatite. Some of them include co-precipitation, sol-gel method, hydrothermal route and electrochemical deposition [4,6,7], solid state reaction [8], and physical methods [9]. HAp nanorods were prepared using different organic surfactant or templates in order to manipulate crystal growth [10-17].

Coelho et al prepared HAp nanorods using CTAB(cetyltrimethylammonium bromide) as a surfactant and obtained diameter between 20 and $50 \mathrm{~nm}$ [18]. According to Sun et al HAp nanorods with diameter 8-15 nm and length $25-50 \mathrm{~nm}$ was achieved by reverse microemulsion method [19]. Salarian et al prepared HAp particles in the presence of CTAB and PEG (poly ethylene gycol) with uniform, rod-like morphology with diamter of 50-80 nm, average aspect ratio of 6-20 [20]. Wei et al prepared fibrinogen fibrils and fibril networks in the absence of thrombin and used as fibrous template for the growth and nucleation of hydroxyapatite crystals [21]. Wei et al also reported the development of HAp nanoparticles onto super water-soluble carbon nanotube-protein hybrid nanofibers to improve its mechanical properties and biocompatibility of composite materials [22]. Su et al developed 3D biaxially orientated polymer nanofibers and bone morphogenetic protein 2 to facilitate the biomineralization of Hydroxyapatite [23].

In this work, we focused on the synthesis of HAp nanorods that resemble bone minerals with narrow size distribution. Nanorods were prepared without the presence of templates and their morphology and crystallinity were characterized by various techniques. The biocompatibility 
test using MG 63 osteosarcoma cell lines confirmed that the synthesized nanorods are biocompatible in nature. Therefore, the HAp nanorods can be used for various biomedical aplications.

\section{Materials and Methods}

\subsection{Materials}

Calcium nitrate and di-ammonium hydrogen phosphate were purchased from Himedia. Ammonia solution was purchased from Merck. All chemicals were analytical grade and used as received without further purification.

\subsection{Preparation of Hydroxyapatite Nanorods}

Calcium nitrate solution $(1 \mathrm{~mol} / \mathrm{l})$ and Di-ammonium hydrogen phosphate solution $(0.6 \mathrm{~mol} / \mathrm{l})$ was added under stirring for one hour. Ammonia solution was added till the solution reaches $\mathrm{pH} 10$ and white precipitate was formed. It was hydrothermally treated at $180^{\circ} \mathrm{C}$ for 6 hrs duration under nitrogen atmosphere and washed with distilled water several times and dried at $70^{\circ} \mathrm{C}$, overnight. The prepared samples weas sintered at $900^{\circ} \mathrm{C}$ for $2 \mathrm{hrs}$ and stored in an air tight container for further analysis. Figure 1 shows the flow chart of HAp nanorods formation in detail.

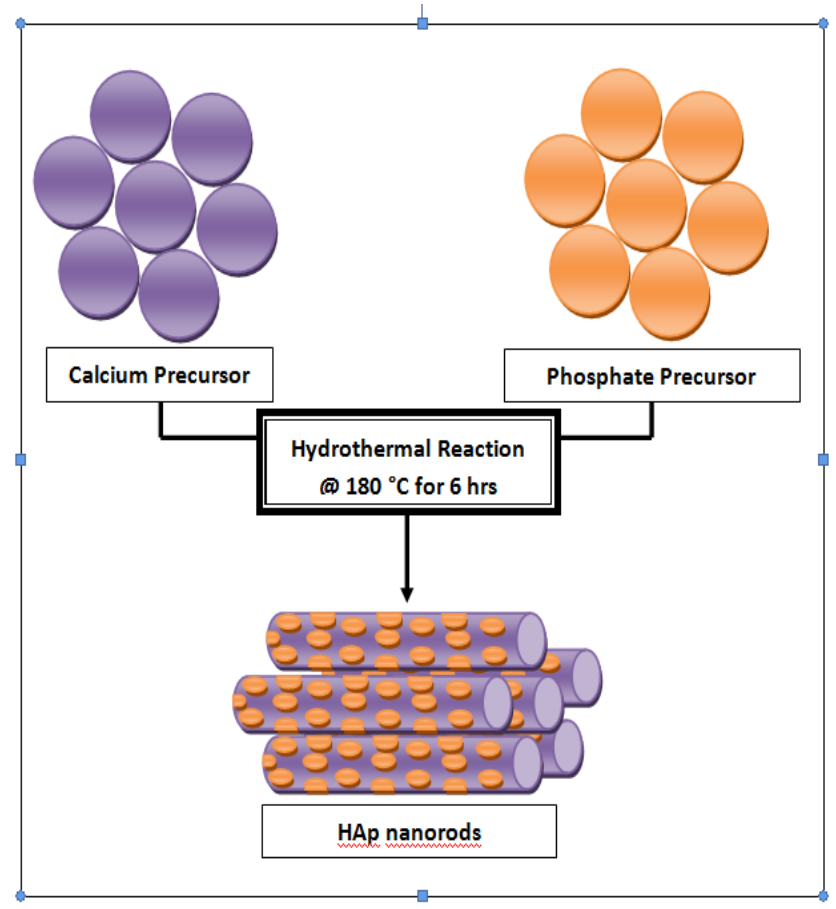

Figure 1. Schematic flow process chart for the synthesis of HAp nanorods

\section{Characterization}

The XRD patterns were recorded using Panalytical, Netherland \& X'pert Powder Diffractometer. The JEOL JEM 2100 High Resolution Transmission Electron Microscope (HRTEM), Carl Zeiss Microscopy Ltd, UK, Sigma Field emission Scanning Electron Microscope (FESEM) and olympus infinity corrected optical research microscope were used to analyze the morphologies of the prepared samples. The human osteosarcoma cancer cell line (MG 63) was purchased from National Centre for Cell Science (NCCS), Pune. It was grown in Eagles Minimum Essential Medium with $10 \%$ fetal bovine serum (FBS) and the cells were incubated at $37^{\circ} \mathrm{C}, 5 \% \mathrm{CO}_{2}$ and $95 \%$ air.

\subsection{Powdr X-Ray Diffractomter (XRD)}

The XRD data of synthesized samples were collected in the $2 \theta$ range from $15^{\circ}$ to $80^{\circ}$ with a scanning speed of $1.2^{\circ} \%$ min. The XRD patterns possessed a strong peak at around $32.2^{\circ}$ corresponding to (211) planes of HAp crystalline structure. Figure 2 shows the X-ray diffraction patterns of the HAp nanorods without the presence of any other phases other than HAp. The narrow peaks represents that the prepared samples are in good aggreement for crystallinity and in good agreement with standard available JCPDS (09-0432).

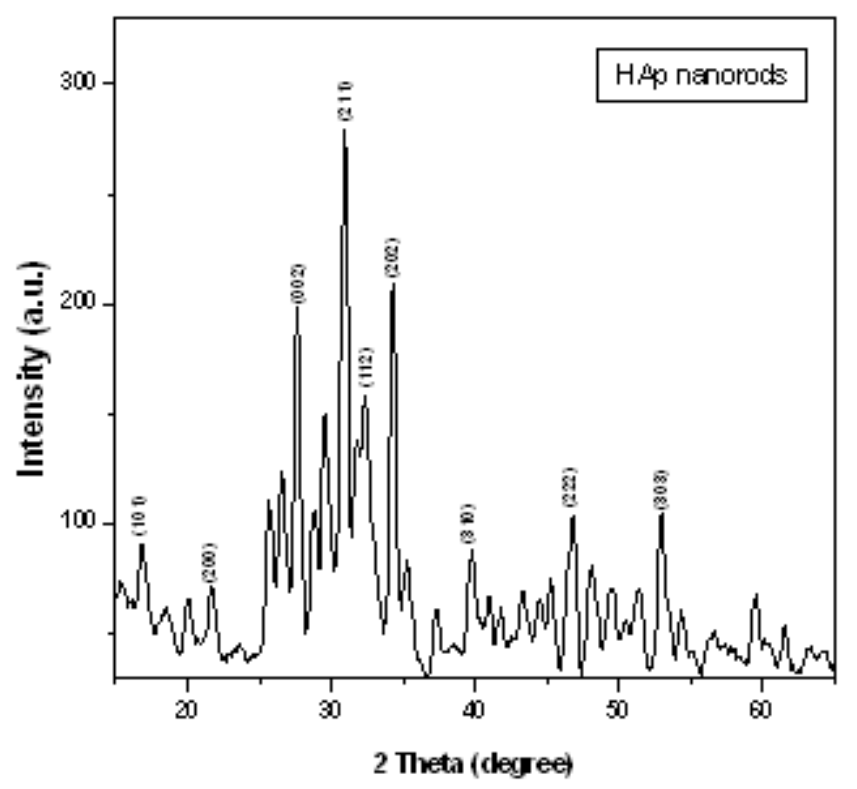

Figure 2. X-Ray diffraction patterns of HAp nanorods

\subsection{Optical Micrographs}

Figure 3 (a) and (b) shows a lower magnification view of optical micrographs for the sample treated at $900^{\circ} \mathrm{C}$. Uniform sizes of HAp nanorods with average length of 20-50 nm were observed. They are monodisperse in nature due to the synthesis method by hydrothermal condition for 6 hours under nitrogen atmosphere at $180^{\circ} \mathrm{C}$. 


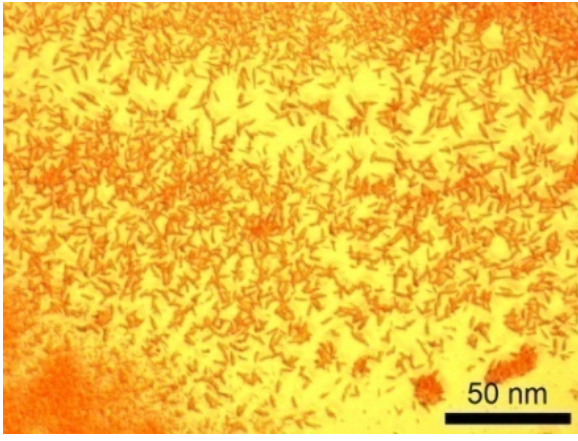

a

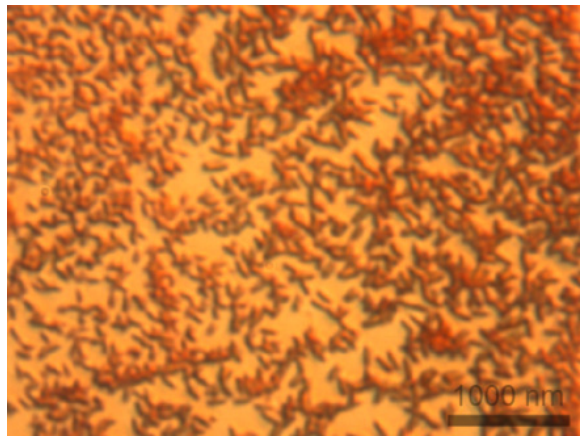

b

Figure 3. Optical micrographs of HAp nanorods

\section{3. $\mathbf{N}_{2}$ Adsorption-Desorption Studies (BET)}

$\mathrm{N}_{2}$ adsorption and desorption isotherm of HAp nanorods is shown in figure 4 . The pore size and pore volume of the samples were obtained according to the Barrett-Joyner-Helenda $(\mathrm{BJH})$ method, and the surface area was measured by the Brunauer-Emmett-Teller (BET) method. The results obtained from the BET analysis are, specific surface area $=22.397 \mathrm{~m}^{2} / \mathrm{g}$, pore volume $=5.602 \mathrm{e}^{-3}$ $\mathrm{cc} / \mathrm{g}$ and pore size $=3.508 \mathrm{e}^{-1} \mathrm{~nm}$. The negative value in the $\mathrm{y}$ axis is due to mesoporous structure.

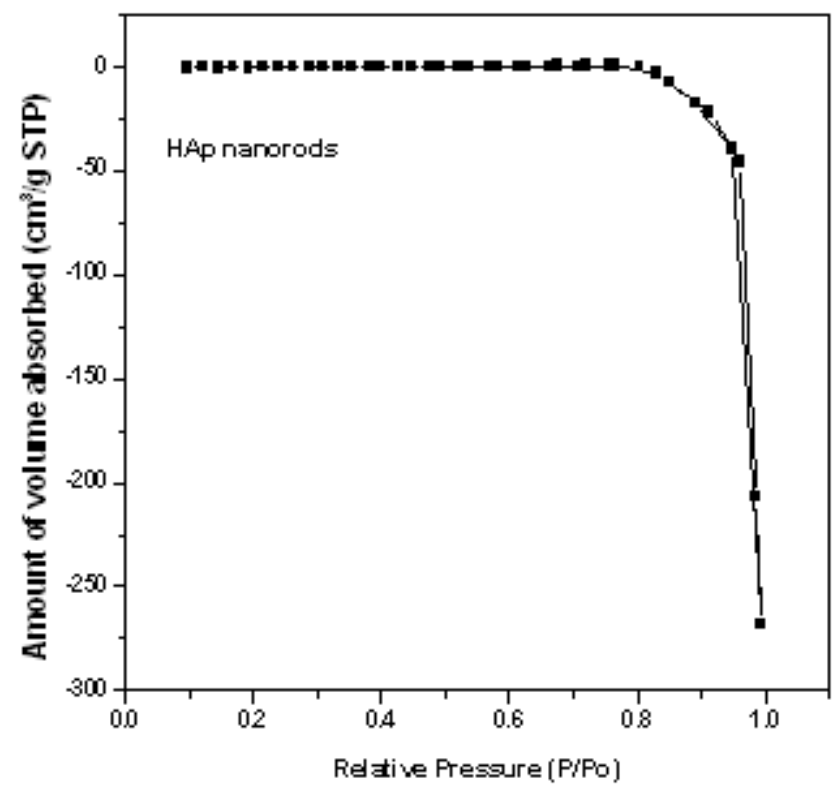

Figure 4. $\mathrm{N}_{2}$ adsorption and desorption isotherm of HAp nanorods

\subsection{Field Emission Scanning Electron Microscope (FE-SEM)}

Bundles of HAp nanorods with well defined, randomly oriented elongated structure were seen in figure 5. This may be due to the influence of hydrothermal treatment during synthesis procedure. FE-SEM results showed regular rod-shaped HAp nanoparticles with a mean diameter of 50 $\mathrm{nm}$ and mean length of $200 \mathrm{~nm}$. The EDAX graph confirms the presence of calcium and phosphate in the prepared samples.

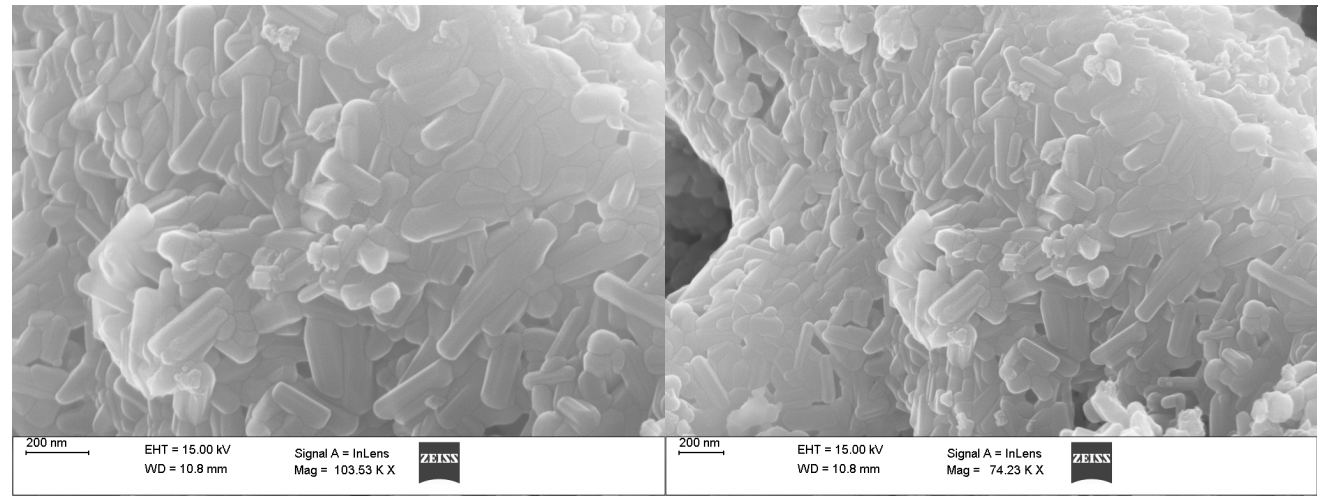

a b

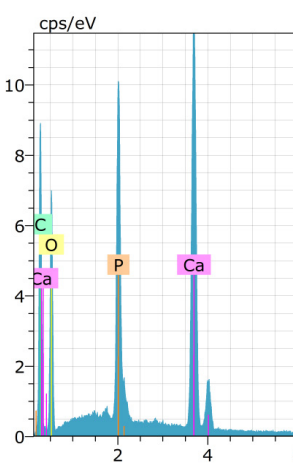

$\mathrm{c}$

Figure 5. (a) and (b) FE-SEM images of HAp nanorods, c) EDAX 


\subsection{Transmission Electron Microscope (TEM) of HAp nanorods}

The TEM analysis were performed in order to obtain quantitative information regarding the exact stoichiometry of the HAp phase formed.TEM images shows that the formed HAp has characteristic nanorod which has a dimension ranges from $20 \times 5 \times 3 \mathrm{~nm}$ to $200 \times 50 \times 5 \mathrm{~nm}$ (figure $6 \mathrm{a}-\mathrm{c}$ ). Most of the rods have $100 \times 25 \times 5 \mathrm{~nm}$ dimension with a aspect ratio of 1:8 (width:length). The HRTEM of HAp nanorods (figure $6 \mathrm{~d}$ ) shows that the predominant (211) plane $\mathrm{C}$ with $\mathrm{d}$ spacing os $\left(2.814 \mathrm{~A}^{\circ}\right)$. it also shows the planes $(002),(112),(300)$ are co-exist as mosaic structure. Figure 6 e shows the electron diffraction pattern of HAp nanorods. The bright rings corresponds to (002), (211), (112), (300) from core to the outwards. This (hkl) corresponds to characteristic and pure HAp nanorods. Figure $5 \mathrm{f}$ confirms the presence of calcium and phosphate in the sample with the $\mathrm{Ca} / \mathrm{P}$ ratio of 1.67 .

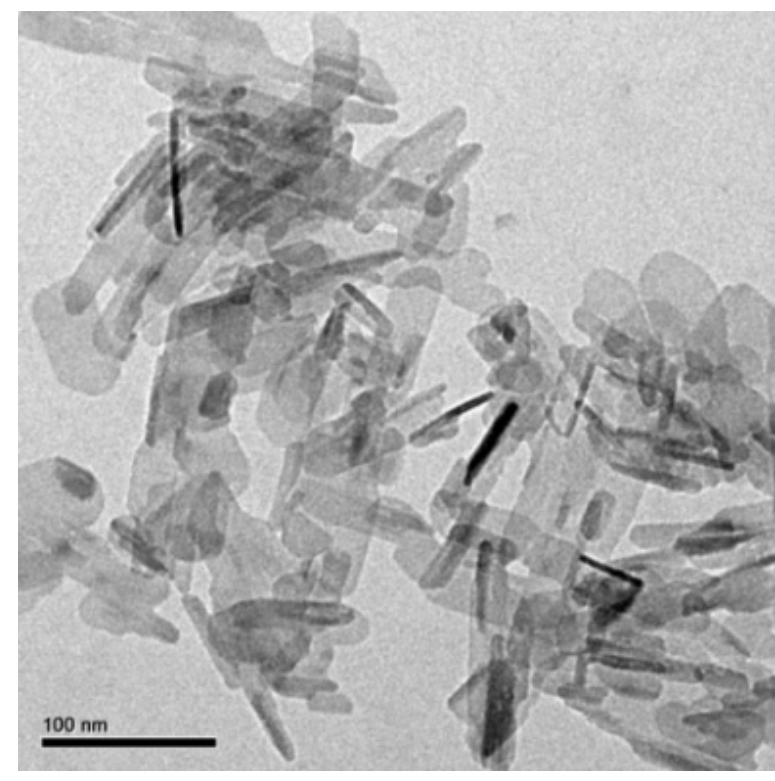

a

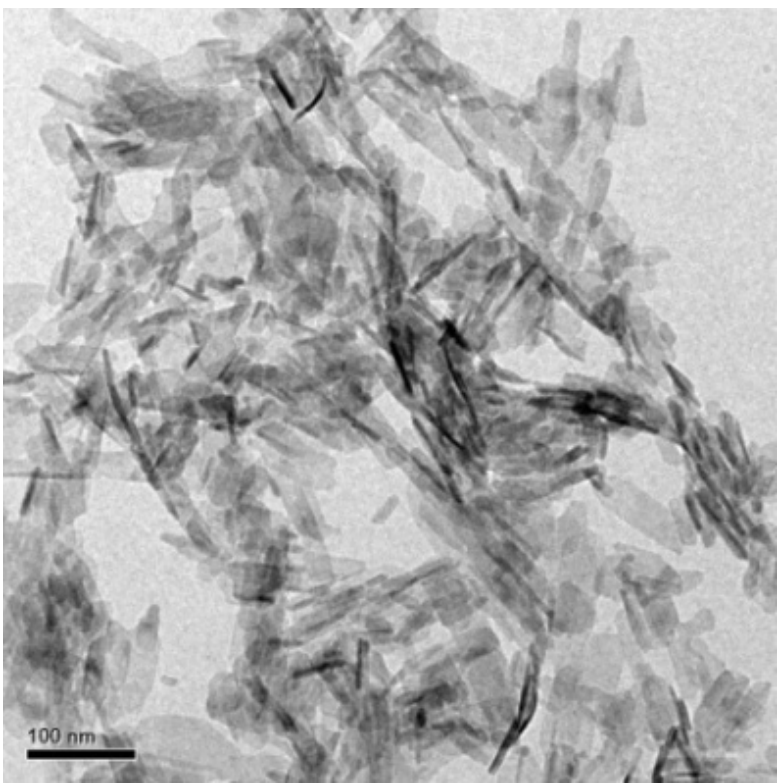

c

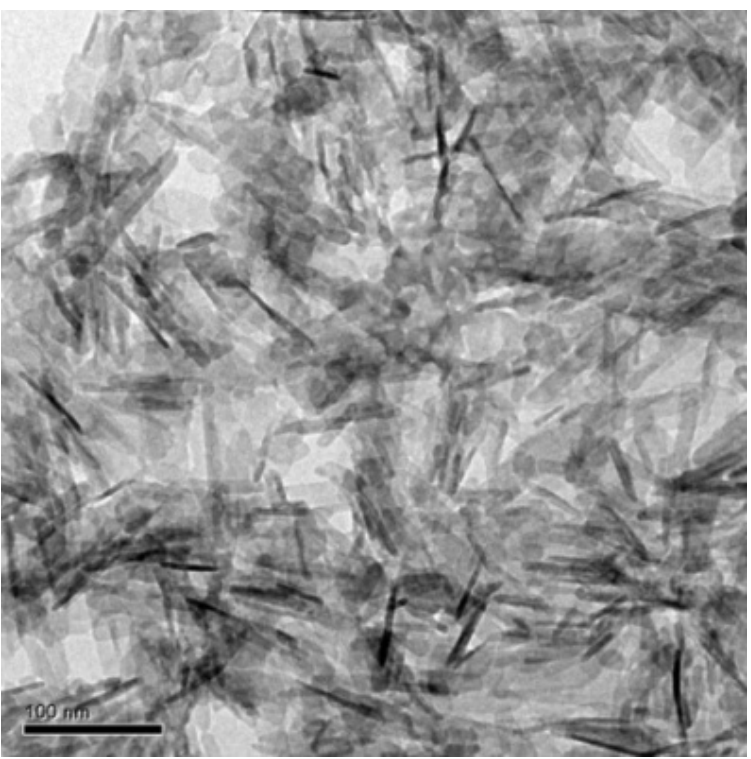

b

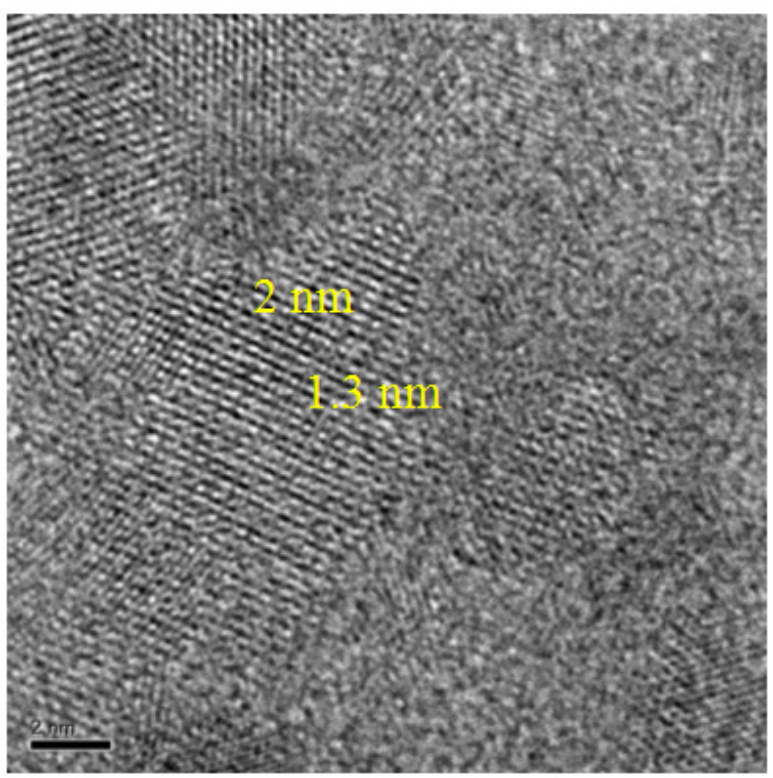




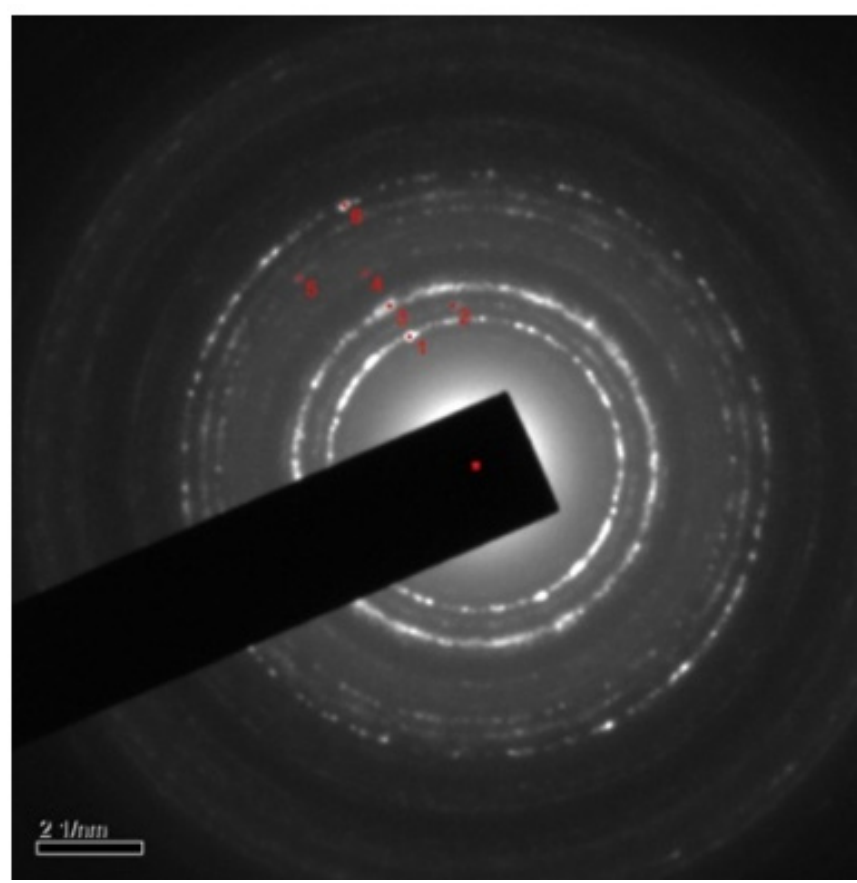

e

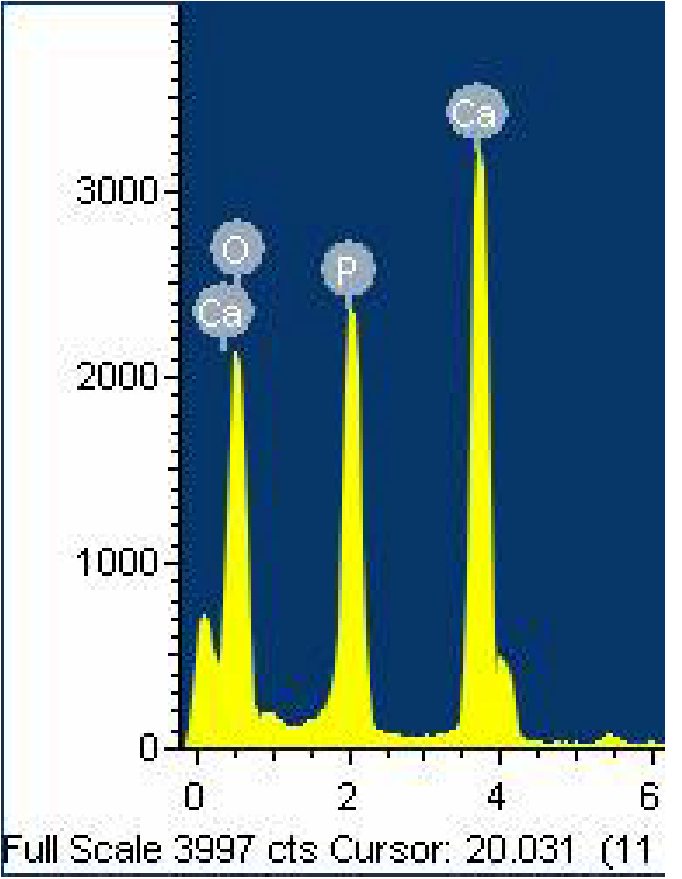

f

Figure 6 a-c). TEM images of HAp nanorods d) HRTEM image e) SAED pattern f) EDAX

\subsection{Invitro Cytotoxicity Study}

As shown in figure 7 at the concentration of $12.5 \mu \mathrm{g} / \mathrm{ml}$, the cell viability of HAp nanoparticles was $100 \%$. However, as the concentration increased from 50 to $200 \mu \mathrm{g} / \mathrm{ml}$ the cell viability was bit lower when compared to the concentration at 12.5 $\mu \mathrm{g} / \mathrm{ml}$. It indicates the carbonate contents have an impact on biocompatibility of HAp nanoparticles against MG 63 cell lines. Cell viability of hydroxyapatite nanoparticles was still maintained above $75 \%$ (figure 8 ) even at higher concentration 200 $\mu \mathrm{g} / \mathrm{ml}$, indicating that the prepared material is highly suitable for biological applications.
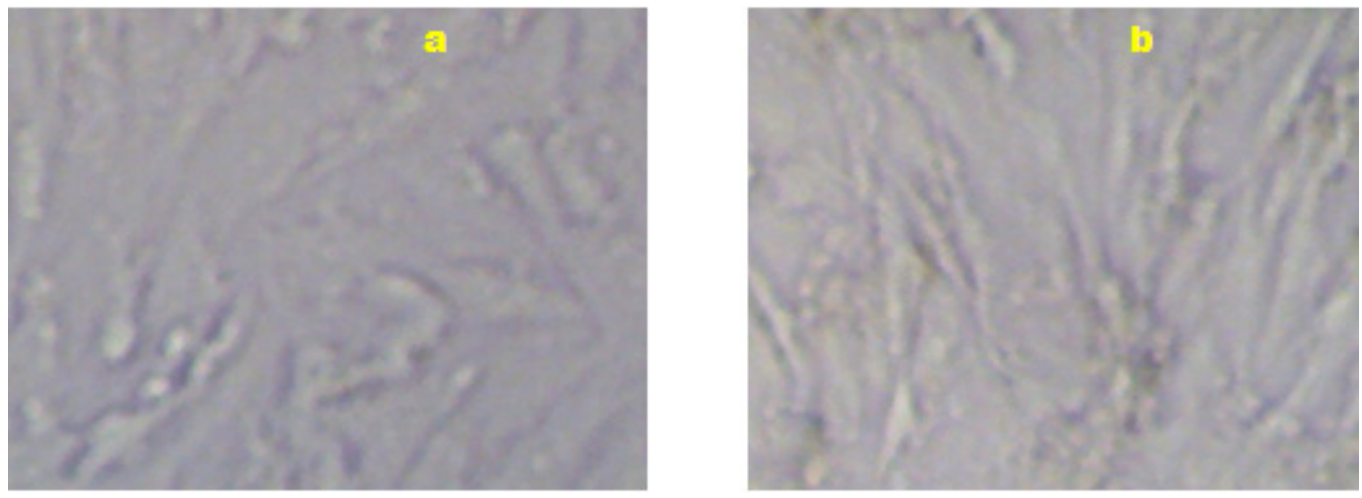

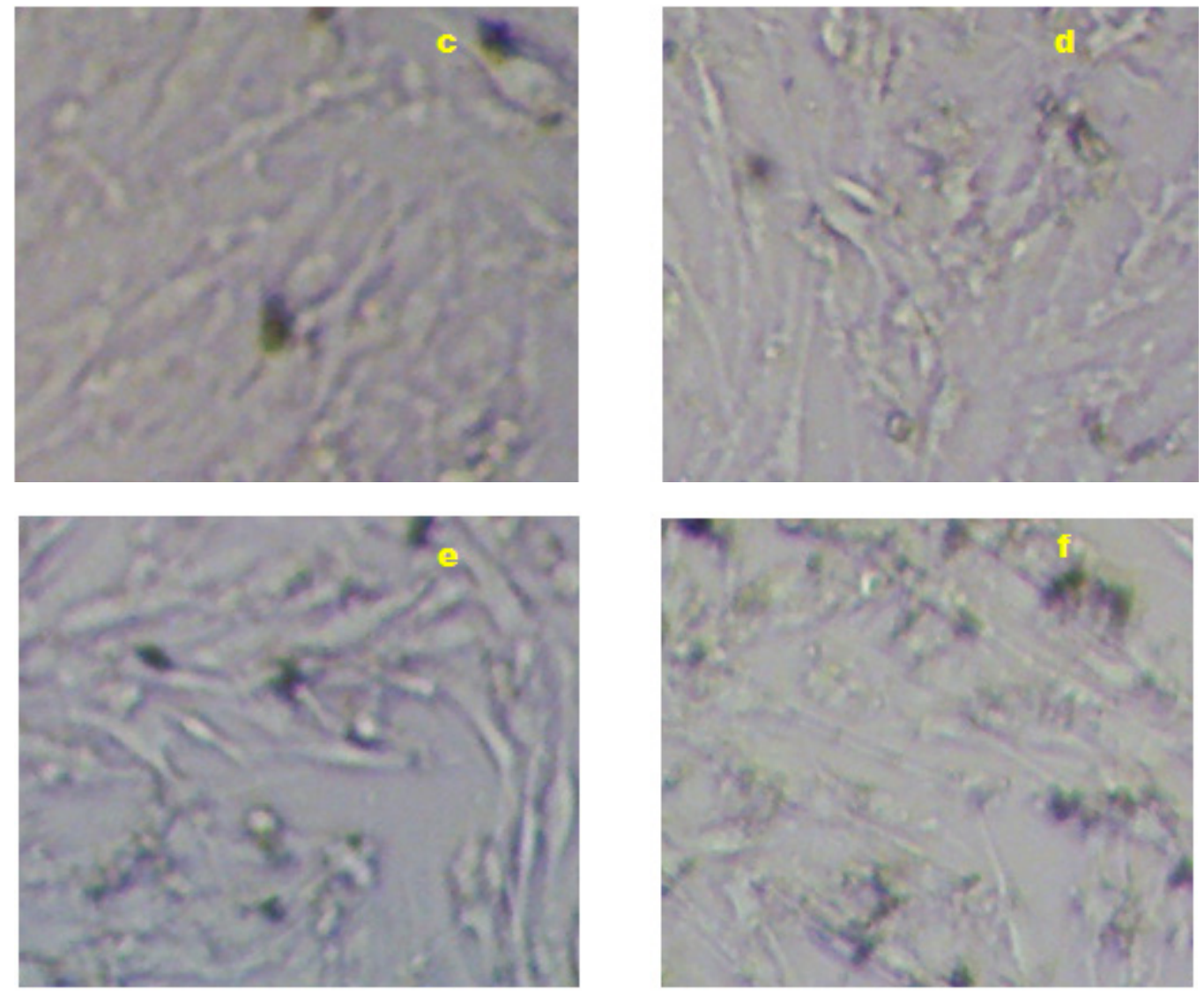

Figure 7. Photomicrographs $(10 \mathrm{X})$ of MG 63 cells after exposure with hydroxyapatite at different concentrations for $48 \mathrm{hrs}((\mathrm{a}) \mathrm{Control} \mathrm{b}) 12.5 \mu \mathrm{g} \mathrm{c}) 25 \mu \mathrm{g}$

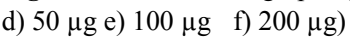

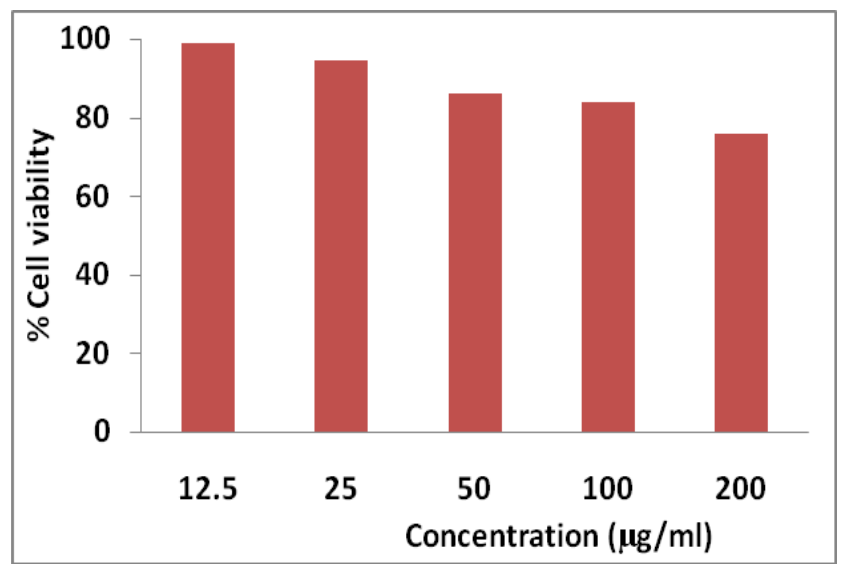

Figure 8. Cell viability of HAp with MG 63 cell lines

\section{Conclusions}

In summary, we have obtained HAp nanorods of controlled size and length without any agglomeration and impurities by simple hydrothermal method. The samples obtained after heat-treatment at temperature in the range 900 ${ }^{\circ} \mathrm{C}$, exhibit very well defined elongated and compact nanorods. This material exhibits good surface area, mesoporous and crystalline structure. The hydrothermal mediated synthesis is a simple, low cost and highly suitable for large scale production of HAp rods and and hence it can be potentially used for various biomedical applications.

\section{Acknowledgements}

The authors are thankful to Head of the Department, Principal and the Management for providing facilities to carry out this research. This work was supported by DST No.SB/S2/CMP-106/2013, New Delhi.

\section{REFERENCES}

[1] Nyuyen Kim Nga, Luu Truong Giang, Tran Quang Huy, Pham Hung Viet, surfactant-assisted size control of hydroxyapatite nanorods for bone tissue engineering, Colloids and Surfaces B: Biointerfaces ,116666 (2014).

[2] Djordjevic Aleksandar, Ignjatovic Nenad, Seke Mariana, Jovi'c Danica, Uskokovic Dragan, and Rakocevic Zlatko, Synthesis and Characterization of Hydroxyapatite/Fullerenol Nanocomposites, Journal of Nanoscience and Nanotechnology, 13, 1 (2013).

[3] Hench LL, Bioceramics, Journal of the AmericanCeramic Society 8, 1705 (1998). 
[4] Fuzeng Ren, Yonghui Ding, Xiang Ge, Xiong Lu, Kefeng Wang, Yang Leng, Growth of one-dimensional single-crystalline hydroxyapatite nanorods, Journal of Crystal Growth, 349, 75 (2012).

[5] Li, P. and de Groot, K., Better bioactive ceramics through sol-gel process, J. Sol-Gel Sci. Technol., 2, 797 (1994).

[6] Li DX, Geng YL, Li YB, Chin J, Inorg Chem 24,83(2008).

[7] Li YB, Wijn J, Klein CPAT, Meer S, Groot, J Mater Sci Mater Med., 5,252 (1994).

[8] Rao RR, Roopa HN, Kannan TS, Solid state synthesis and thermal stability of HAP and HAP - beta-TCP composite ceramic powders, J Mater Sci Mater Med 8,511 (1997).

[9] Darr JA, Guo ZX, Raman V, Bououdina M, Rehman IU, Metal organic chemical vapour deposition (MOCVD) of bone mineral like carbonated hydroxyapatite coatings, Chem Commun., 6, 696 (2004).

[10] D.Jiang, J.Zhang, Current Applied Physics Calcium phosphate with well controlled nanostructure for tissue engineering, 9S252 (2009).

[11] J.D Chen, Y.J Wang, K.Wei, S.H Zhang,X.T Shi, Self-organization of hydroxyapatite nanorods through oriented attachment Biomaterials, 28, 2275 (2007).

[12] S.Manafi, M.R Rahimipour, Synthesis of Nanocrystalline Hydroxyapatite Nanorods via Hydrothermal Conditions Chemical Engineering Technology, 34, 972 (2011).

[13] A.Zhu,Y.Lu,Y.Si,S.Dai,Frabicating hydroxyapatite nanorods using a biomacromolecule template Applied Surface Science, 257,3174 (2011).

[14] Y.Wang, S.Zhang, K.Wei, N.Zhao, J.Chen, X.Wang, Hydrothermal synthesis of hydroxyapatite nanopowders using cationic surfactant as a template Materials Letters, 60, 1484 (2006).
[15] Y.Liu, W.Wang, Y.Zhan, C.Zheng, G.Wang, A Simple Route to Hydroxyapatite Nanofibers, Materials Letters, 56, 496 (2002).

[16] X.Wang,J.Zhuang,Q.Peng,Y.D Li, Liquid-Solid-Solution Synthesis of Biomedical Hydroxyapatite Nanorods Advanced Materials, 18, 2031 (2006).

[17] F.Zhang,ZH.Zhou, SP. Yang,LH. Mao, HM. Chen, XB. $\mathrm{Yu}$, Hydrothermal synthesis of hydroxyapatite nanorods in the presence of anionic starburst dendrimer, Materials Letters 59, $1422(2005)$.

[18] J.M. Coelho, J. Agostinho moreira, and A. Almeida, Synthesis and characterization of HAp nanorods from a cationic surfactant template method, Journal of Materials Science: Materials in Medicine, 21, 2543 (2010).

[19] Yuxiu Sun, Guangsheng Guo, Zhihua Wang, Hongyou Guo, Synthesis of single-crystal HAP nanorods, Ceramics International, 32, 951(2006).

[20] Salarian M, Solati-hashjin M., Shafiei S. Sara, Goudarzi A, Salarian R., Nemati A, Surfactant-assisted synthesis and characterization of hydroxyapatite nanorods under hydrothermal conditions, Materials Science, 27, 961(2009).

[21] Wei G, Reichert J, Bossert J \& Jandt KD, Novel biopolymeric template for the nucleation and growth of hydroxyapatite crystals based on self-assembled fibrinogen fibrils, Biomacromolecules, 9, 3258-3267 (2008).

[22] Wei G, Zhang J, Xie L \& Jandt KD, Biomimetic growth of hydroxyapatite on super water-soluble carbon nanotube-protein hybrid nanofibers, Carbon, 49, 2216-2226 (2011).

[23] Su Z, Li J, Ouyang Z., Arras MM., Wei G \& Jandt KD, Biomimetic 3D hydroxyapatite architectures with interconnected pores based on electrospun biaxially orientated PCL nanofibers, RSC Advances, 4, 14833-14839 (2014). 